\title{
A BIBLIOCLASTIA COMO MECANISMO DE CONTROLE SOCIAL
}

\author{
Josiel Machado Santos \\ Bibliotecário-Documentalista da \\ Universidade Federal de Minas \\ Gerais, Campus Montes Claros. \\ Especialista em Gestão de Bibliotecas \\ Públicas pela AVM Faculdade \\ Integrada. \\ E-mail: lordjosiel@yahoo.com.br
}

\begin{abstract}
RESUMO
Os livros, entendidos como sistemas que representam fontes de informação e de conhecimento na sociedade, avaliam a realidade de modo a fornecer diferentes visões do que ela trata a partir de suas funções como transmissor de cultura e de contribuição para a preservação da memória coletiva. Assim, a representação de um ou mais pontos de vista parece ser a tarefa desses sistemas. Nesse sentido, a cooptação da liberdade de expressão e do acesso ao conhecimento está relacionada com a supressão de determinados pontos de opinião. Isto pode ocorrer através do método particular de queima de livros, sendo, portanto entendido como um mecanismo de controle social. Para basear essa premissa, se usará dois conceitos: o arquétipo (Jung) e o dispositivo (Foucault, Deleuze, Agamben). Conclui-se que a biblioclastia, representada pela queima de livros, tem o único propósito da supressão da cultura e da memória coletiva, objetivando a manipulação da sociedade, da liberdade de expressão e da diversidade de valores.
\end{abstract}

Palavras-chave: Biblioclastia. Controle social. Arquétipo. Dispositivo.

BIBLIOCLASTY AS A SOCIAL CONTROL MECHANISM

\section{ABSTRACT}

Books, defined as systems that represent sources of information and knowledge in society, assess the reality in order to provide different views of it comes from his duties as a transmitter of culture and contribution to the preservation of collective memory. Thus, the representation of one or more views seems to be the task of these systems. In this sense, the appointment of freedom of expression and access to knowledge is related to the removal of certain points of view. This can occur through the particular method of burning books, and therefore understood as a mechanism of social control. To base this premise, it will use two concepts: the archetype (Jung) and the 
device (Foucault, Deleuze, Agamben). It concludes that the biblioclasty, represented by the burning of books, has the sole purpose of suppression of culture and collective memory, aimed at the manipulation of society, freedom of expression and diversity values.

Keywords: Biblioclasty. Social control. Archetype. Device.

\section{INTRODUÇÃo}

Este estudo abordará, em primeiro lugar, os livros, a leitura e literatura como insumos culturais e como instrumentos de memória coletiva. A ênfase em si, será dedicada ao pensamento sobre a degeneração de suas funções e a diversidade na promoção do livro, a partir de relações de poder que transcendem às comunidades e atravessam os mais distintos pontos de vista que estas compõem, se materializando em sua queima. A análise desse fenômeno como um mecanismo de controle social é o ponto central deste estudo. A este é adicionado à queima de livros que se constitui como a negação da diversidade inerente à natureza humana.

Para fundamentar este argumento, serão utilizadas duas ferramentas metodológicas: em primeiro lugar, a noção de arquétipo trabalhada por Carl Gustav Jung (2000a) que se refere a uma manifestação da herança psíquica dos homens com ênfase no inconsciente coletivo que pode ser apresentado sob a forma atemporal e aespacial, possibilitando a criação de línguas, a extensão da consciência e do conhecimento. No entanto, ele pode ser distorcido e causar malformações na estrutura psicossocial e no modo como as sociedades são perfiladas por indivíduos e vice-versa. 0 outro, o conceito de dispositivo, trabalhado por Foucault (1999), Deleuze (1990) e Agamben (2011), cuja raiz comum é a de ser um aparato de controle que constantemente se reatualiza em práticas cotidianas, opiniões e na configuração das esferas públicas.

\section{LIVROS, LEITURA E LITERATURA: INSUMOS CULTURAIS E INSTRUMENTOS DE MEMÓRIA COLETIVA}

Em seu antológico conto "A Biblioteca de Babel”, escrito em 1934, Jorge Luis Borges (1999) diz que um livro que ninguém tenha lido nada mais é do que um cubo de papel com folhas. A partir disso, pode-se supor que a leitura é o que dá 
importância, projeção e existência de modo que transmite uma mensagem através de um texto, seja ele qual for. 0 papel do texto é bilateral, porque, por um lado, a escrita (entendida aqui como emoções, sentimentos, visões de mundo, histórias, experiências), e por outro, a leitura (apropriação de histórias, cultura, as pretensões objetivas que quer mostrar o 'escritor' e seu espaço para a interpretação (RICOEUR, 2009). Quanto ao primeiro ponto, Deleuze (1997, p. 11) afirma que

\begin{abstract}
Escrever não é certamente impor uma forma (de expressão) a uma matéria vivida. A literatura está antes do lado informe, ou do inacabamento [...]. Escrever é um caso de devir, sempre inacabado, sempre em via de fazer-se, e que extravasa qualquer matéria vivível ou vivida. É um processo, ou seja, uma passagem de vida que atravessa o vivível e o vivido.
\end{abstract}

Por trás da escrita se acredita que há um mundo dentro do mundo. Assim, o que foi ou que pode ser escrito define os limites que não podem ser excedidos. Wittgenstein $(1994, \S 5.6)$ diz que "os limites da minha linguagem são os limites do meu mundo". No entanto, esse mundo que se projeta tanto em si (o eu), como no outro, por conseguinte, é o limite da língua externa, isto é, as visões e percepções que podem se ter sobre ele. Também há outro argumento que mostra como o indivíduo se apropria de um texto alheio, tornando-o seu através da leitura. Então toda obra é uma viagem; um trajeto que só pode ser percorrido por caminhos exteriores levando em conta as trajetórias interiores que o compõem.

Escrever não é apenas estabelecer uma forma de expressão de uma vivência. É um assunto de futuro, que não acaba, está sempre em movimento e que ultrapassa qualquer acontecimento suscetível de ser vivido ou então já passado. A escrita é inseparável do devir (do futuro), pois este é encontro da proximidade e da indiferenciação, de modo que não se pode descobrir sobre o que exatamente está se falando (DELEUZE, 1997). 0 objeto aparece indeterminado, cabendo àquele que está no intento de atribuir um sentido dar um significado exterior a linguagem. 0 escritor é como uma entidade que fornece percepções para serem recebidas e que, retornando de alguma maneira, tem o poder de criar infinitas redes em que se germinam as ideias.

O que se produz com a escrita deve-se ter alguma utilidade na prática. Com o pensamento crítico acontece fenômeno bem particular, pois ao analisar ou 
avaliar os fundamentos e consistência das diferentes questões que geram argumentos suscetíveis de apropriação, por meio dos sentidos do sujeito que pretende interpretar/representar o mundo com uma digna resposta a uma interrogante humana (as que admitem muitas respostas e não apenas uma), o ato de escrever cria nas pessoas um dispositivo de comunicação prática, uma díade entre diferentes percepções e de como se poderia repensar o mundo. 0 pensamento crítico é projetado principalmente para o interior (no eu), então o processo de alteridade é unido a este, isto é, quando existe uma relação com o outro, com o exterior.

Chartier (1998) cita que o importante é seguir a trajetória de cada texto, desde o manuscrito ou ditado pelo autor até a sua leitura pelos leitores. Sem contrariar o que foi dito nos parágrafos anteriores, o mesmo Chartier (2012), em outro texto, diz que a produção de livros tem associado múltiplos atores, mas no final, é o conteúdo cultural, regada por uma série de redes que influenciam o universo cognitivo das comunidades. As práticas de leitura têm manipulado a articulação entre textos, que possibilita a criação de novas histórias. Assim como o escritor idealiza seu mundo, o hermeneuta tem sua função e, como este, os indivíduos compreendem uma história já existente.

A leitura, os livros e, em geral, a literatura, deu aos homens os meios para sair de uma "autoculpa da menoridade" (KANT, [20--]), ou seja, a impossibilidade de usar sua inteligência sem a orientação de outro. E eles são culpados, porque sua causa não reside na falta de razão, mas de determinação e coragem para recorrer a ela sem a orientação. Todavia "sem orientação de outro" significa a necessidade de ter a preocupação de procurar a verdade e conhecimento em si mesmo. A cultura vulgarmente - se encontra nos livros e, como tal, está disponível para que as pessoas possam utilizá-la para se instruírem. O processo outorga ao escritor, inicialmente, os insumos culturais para uma sociedade, que são então assimiladas, tal como é conhecido.

Muitos livros são escritos diariamente e são um suporte para se registrar "algo" (uma emoção, uma experiência...), logo, constituem uma "memória coletiva" (HALBWACHS, 2004), que é uma corrente de pensamento contínuo, de uma continuidade que não tem nada de artificial, mas que retém do passado aquilo que se encontra vivo e que também seja capaz de viver na consciência de um grupo que 
a cultiva. Por definição, não excede os limites deste. No entanto, em seu desenvolvimento não existem linhas de separação claramente traçadas, como na história, mas limites irregulares e incertos. A constituição da memória não deve ser compreendida apenas com base em eventos factuais que mudam a realidade de uma comunidade (daí a pergunta: qual magnitude deveria ter sido feita para tornálo assim?), mas intervindo na forma como a cultura tem, em geral, se manifestado: por meios pictóricos, escrituras e outras formas de comunicação que constituem uma espécie de esfera pública que não é mais do que

o lugar (real, imaginário ou simbólico) onde fluem as mensagens, opiniões e interesses, onde cada um poderá, se quiser, contemplar as opiniões e argumentos dos demais (indivíduos, grupos, correntes de opinião, etc.), expor suas opiniões e participar no diálogo público e, no pior ou no melhor dos casos, aceitá-lo como lugar-comum de referência aberto a todo o mundo [...] (MONZÓN, 1996, p. 262, tradução nossa).

A memória liga a história de uma comunidade ou de um povo. Se não há memória, não há história. Se os livros que são escritos constituem parte da bagagem cultural de uma comunidade, é aí que está organizado tudo o que acontece em algum momento de sua história. Agora, este continua a ser um problema secundário, se olharmos para o progresso tecnológico que tem permeado a cultura e suas manifestações atuais; em que já não é tão fácil de destruir os vestígios de um determinado rito. Um exemplo a esse respeito pode ser encontrado na sátira de George Orwell (2012), onde numa granja, desde cedo, o porco Napoleão estabeleceu as regras de 'convivência' a sua vontade, pois sabia que os demais animais do lugar possuíam uma memória precária. Isto é o mesmo que a supressão de elementos de modo que a memória de gerações futuras já não tem vestígios de "história" da comunidade.

A memória em si, não é boa nem má, depende do seu uso. Incluindo, claramente, a sua não supressão, um povo (e suas futuras gerações), adquire consciência e liberdade. Eliminá-la ou parcializá-la, torna-se um jogo de fatos. 0 defeito está na máxima orwelliana onde "quem controla o passado, controla o presente e o futuro". No entanto, sobre este assunto, Todorov (2002; 2008) proclama a ideia de "exame da razão" e "prova do debate" contra duas atitudes prejudiciais para um corpo social: a sacralidade da memória (o isolamento da 
memória para torná-la inútil como uma lição para o presente) e banalização (a assimilação abusiva do presente para o passado). Por exemplo, a primeira cita Francisco Franco (ditador espanhol) como um monstro inefável e irrepetível; o segundo vê este personagem em cada canto do mundo, como Jorge Rafael Videla (na Argentina), Augusto Pinochet (no Chile), Alfredo Stroessner (no Paraguai), dentre tantos outros.

Os livros constituem o progresso intelectual de uma comunidade, outorgando cotas de cultura, permitindo que se construa um relato histórico, constituindo sua memória. Em suma: incitam-nos a nos encontrarmos com nós mesmo. Criá-los é uma arte, difundi-los uma prática, lê-los uma forma de vida. E destruí-los? A seção seguinte tentará esclarecer este ponto.

\section{QUEIMA E CONTROLE SOCIAL}

No vocabulário comum, 'queima de livros' se refere a um ato que envolve a destruição pelo fogo de livros e outros materiais escritos. Isso geralmente é realizado publicamente, a fim de censurar ou vetar determinadas ideias. Tem suas raízes, geralmente, nas objeções culturais, religiosas ou políticas que os textos estão queimando com "versões oficiais" de uma determinada questão ou problema. São baseadas em ideias que ameaçam o status quo estabelecido (e aparentemente estável). As incertezas sociointelectuais das ações junto da realidade cotidiana são cúmplices na destruição do patrimônio cultural (BERGER; LUCKMANN, 2006). Deve-se notar que a queima se refere principalmente aos livros, mas se estende a produtos artísticos desde discos musicais até esculturas, passando até por muros pintados a grafite, dentre outras manifestações.

Esta prática/ação de destruição não é nova. Isso já aconteceu na China Antiga da Dinastia Qin, no Egito (enquanto província romana) com a incineração da Biblioteca de Alexandria, na queima de escolas não-cristãs sob Teodósio I, nas escaramuças intelectuais e culturais de árabes e espanhóis na península ibérica (quando Toledo foi reconquistada em 1085, os espanhóis queimaram os escritos eruditos árabes, assim como Tomás de Torquemada, em Granada, antes de sua captura iminente pelos espanhóis, ordenou a queima todos os materiais não- 
cristãos), a censura robespierreana no tempo da Revolução Francesa contra todos aqueles que pregavam o catolicismo, o clericalismo e o absolutismo.

Existem ainda outros exemplos que não são indiferentes dos já citados: a) o “auto de fé da Universidad Central", em 1939, que fez queimar em solo ibérico autores que iam de Voltaire a Freud; b) o bibliocausto nazista, que censurou desde cientistas a artistas, passando por filósofos, sociólogos, entre outros (BÁEZ, 2002); c) a queima organizada pela ditadura argentina, que chegou ao poder depois de derrubar o governo peronista, em 1976. Desse golpe, a fala de Luciano Menéndez, chefe do terceiro corpo do Exército, assentado em Córdoba, no jornal "La Opinión" - em sua edição de 30 de abril de 1976 - fica a síntese do pensamento do novo regime: "Da mesma maneira que nós destruímos pelo fogo a documentação perniciosa que afeta o intelecto e o nosso modo de ser cristão, serão destruído os inimigos da alma argentina".

Sobre esta declaração, as palavras da investigadora chilena Lucy Oporto Valencia (2012a), parece bastante certeira:

A destruição de arquivos, registros, documentos, testemunhos, livros, filmes, fotografias e obras de arte em geral, entre muitas outras representações humanas, situam no contexto do mal na história, a luta pelo poder e a "visão da existência como perpétua atrocidade" que sustenta obscuramente, unida ao destino dos vencidos, a individualização e a desrealização simultânea destes, em suas perdas e ausências. Seu propósito é, no princípio, destruir a memória e, por fim, destruir a consciência, o conhecimento e toda a possibilidade de acesso a estes, com o fim de estabelecer e consolidar uma nova ordem política, social e cultural que seja imune a crítica de modo radical e permanente, e que a violência e perversão inerente a sua expansão e implantação sejam naturalizadas, deste modo, de maneira eficaz e indolor, sob a égide das instituições do Estado e dos poderes que o controlam (Tradução nossa).

Não é possível ser mais claro: sempre há uma entidade organizada, para assumir a supressão da cultura e realizar atividades que influenciam a memória coletiva. Neste caso, o agente que queima livros, o faz para impor seus termos ou para preservar a ordem e, por isso mesmo, tem sido o responsável pela implementação zelosa da mesma em sua comunidade. 0 exercício desse controle social então pode ser discutido por duas noções teóricas: por um lado, o arquétipo junguiano e, por outro, o conceito de dispositivo. 


\subsection{Arquétipos e repetição}

O inconsciente coletivo é pensado por Jung (2000a) como o reservatório de nossas experiências como espécie; uma classe de conhecimento inato e compartilhado por todos os homens. Mesmo assim, nunca totalmente cientes disso. Em sua base, se forma uma espécie de influência em todos os nossos comportamentos e experiências, particularmente no plano emocional. No entanto, o conhecimento das situações acima, só vem a partir da percepção dessas influências. No inconsciente coletivo, existem algumas experiências que ensinam, de maneira mais vivaz, os efeitos desta parte da psique, entre outros, déjà vu (já visto), o reconhecimento imediato de símbolos e significados dos mitos.

Em particular, compreender as implicações do inconsciente coletivo abre caminho para o conceito de arquétipo, que é nada mais é que uma manifestação da herança psíquica da humanidade concentrada no inconsciente coletivo cujos processos e formas podem aparecer e reaparecer independente das coordenadas de tempo e espaço. Seu desenvolvimento torna possível a criação de símbolos, ampliando a consciência e conhecimento. A obstrução de tal desenvolvimento pode conduzir a um estado de inconsciência desprovido do conhecimento (JUNG, 2000b).

E é a recorrência desta prática que poderia conceder a imagem do personagem ou experiência arquetípica, mas é a luta perpétua entre conhecimento e ignorância, entre o desenvolvimento da capacidade de consciência e o estado de inconsciência e, finalmente, entre a luz e as trevas (VALENCIA, 2012b). Queimar livros é mortal para uma cultura. Nesse sentido, envolve diretamente a falta de acesso ao conhecimento e encontro com nós mesmos, e muito pior, a incapacidade de desenvolver uma imagem arquetípica da mesma queima de livros, esta, a fim de ampliar e sensibilizar tanto individualmente como coletivamente.

O controle social exercido por aquele que queima livros é a obstrução de acesso ao conhecimento, para em seguida, modificar a realidade, que de acordo com Eliade (1992), é adquirido apenas através de repetição ou participação, pois tudo que não tem um modelo é "sem sentido", ou seja, carece de realidade. Por esta razão, os homens têm, assim, a tendência de se tornarem arquetípicos e paradigmáticos. E com isso determinando os seus destinos, objetivados em 
número e naturalizando essa censura numa normalidade que é então aceita pelas pessoas (que é o mesmo que obedecer a versão "oficial").

Isto é algo similar ao que Orwell (2009) mostra em sua distopia “1984”, com um Ministério da Verdade que destrói sistematicamente os documentos históricos e os reescrevem continuamente segundo as necessidades do governo do momento. A generalização de uma patologia psíquica coletiva é o que se tentou retratar com a introdução do conceito junguiniano de arquétipo.

\subsection{Dispositivos e máquinas}

Em toda sociedade a produção do discurso é ao mesmo tempo controlada, selecionada e redistribuída por uma série de procedimentos que são projetados para afastar os poderes e perigos, dominar o acontecimento aleatório e esquivar à sua pesada e terrível materialidade (FOUCAULT, 1996).

À primeira vista, estes procedimentos podem ser os livros. Agora, quem os utiliza, podem canalizá-los à sociedade através, por exemplo, do controle de preferências e consumo cultural e informativo da sociedade. 0 discurso em si, para Foucault (1996) é o desejo, o objeto e, em última análise, o que se deseja apropriar. No esquema, acrescentam-se as relações inerentes a toda sociedade e é adicionado ao conceito de dispositivo. Um mecanismo que tece significado para a vida humana, mas que não permite a verdadeira emancipação e livre arbítrio de pensamento e ação.

No entanto, há três significados do conceito em uso: Foucault, Deleuze e Agamben. 0 primeiro afirma que é um grupo heterogêneo que inclui o linguístico e o não-linguístico, discursos, instituições, leis e disposições filosóficas, entre outros, formando uma "rede" e um vínculo difuso entre estes elementos. 0 segundo afirma que a função deste é concreta e dominante, também quase sempre atribuída a uma estreita relação com o poder. 0 terceiro, dada a sua generalidade, inclui episteme, conhecimento específico da realidade que distingue o científico do não científico (FOUCAULT, 1999). 
O segundo é o mais preciso e pode ser conceituado como

uma espécie de esfera de um conjunto multilinear, composto por linhas de diferente natureza [...], que não cobrem nem cercam um sistema, pois cada um dos quais seria homogêneo por conta própria (o objeto, o sujeito, a linguagem), mas seguem direções diferentes, formando processos sempre em desequilíbrio e, estas linhas, tanta estão perto como se distanciam umas das outras. Cada linha está quebrada e submetida a variações de direção [...]: os objetos visíveis, a formulação de enunciados, as forças em movimento e os indivíduos posicionados como vetores (DELEUZE, 1990, p. 155, tradução nossa).

O terceiro conceito diz que o dispositivo é qualquer coisa que tenha de algum modo a capacidade de capturar, orientar, identificar, interceptar, modelar, controlar e assegurar os gestos, as condutas, as opiniões e os discursos de seres viventes. Não só, por conseguinte, nas prisões, nos manicômios, no panóptico, nas escolas, nas fábricas, nas medidas jurídicas, etc., cuja conexão com o poder é, em certo sentido, evidente, mas também na escrita, na literatura, na filosofia, na agricultura, nos computadores, nos telefones celulares e, por que não, na própria linguagem, que "[...] sem perceber as consequências que se seguiriam, teve a inconsciência de se deixar capturar" (AGAMBEN, 2011, p. 257-258, tradução nossa).

Em Foucault, a queima de livros vem da própria prática, quando se torna um discurso de controle. Deleuze, por sua vez, tem a aplicação desta ideia a partir das consequências que acontece com a destruição dos livros: a perda total de seu conteúdo. Agamben, através da assimilação dos discursos, tem uma posição semelhante à de Foucault.

0 ponto em comum entre os três autores é que eles reconhecem que o dispositivo, qualitativamente, pode ser qualquer elemento ou objeto produzido e institucionalizado na realidade cotidiana, de forma que o sujeito transforma o caos através da ordem (controle), estabelecendo esta rede. Produz o mesmo resultado, ou seja, uma constante reconfiguração que ocasiona subjetividades em cada momento histórico; condiciona um determinado espaço de realidade. 0 dispositivo orienta práticas singulares, condiciona os comportamentos dentro de um espaço definido que é, em si, imensurável. Nessa lógica, produzem sujeitos dominantes de uma ordem do discurso cuja estrutura detém uma reivindicação (ou regime) da 
verdade. A queima de livros joga sobre este argumento uma articulação sobre uma determinada realidade de uma rede de poder-saber.

A ideia do dispositivo é a mesma questão orwelliana de 'quem controla o passado, controla o presente e o futuro' e comparável também, ao uso dos bombeiros para queimar os livros no romance "Fahrenheit 451", de Ray Bradbury (2012). A supressão e controle da cultura dão origem a vícios como a fragmentação, desproporcionalização e abuso de poder nas comunidades em que se objetiva impor um único entendimento do mundo, com a exclusão da liberdade de expressão e valorização da diversidade.

\section{CONSIDERAÇÕES FINAIS}

Quando não lembramos, inevitavelmente repetimos. É necessário lembrar para fazer diferente e ser capaz de suspender a agressão, afirmando o direito de falar entre nós. Sobre a memória coletiva nós reconstruímos o passado, mas sempre tendo em conta os imperativos do presente com base em um horizonte de expectativas para a criação de respostas a um tempo futuro.

No entanto, a construção de expectativas emerge no tempo presente, que contém e concebe a experiência passada e expectativas futuras. Esta é então a matriz de expectativas e de memória. Sob estas reflexões está à chave da memória para o exercício wittgensteniano de subir a escada e chutá-la; não se calar e caminhar para a unidade e uma sociedade que não vê dentro de si seu pior inimigo: o esquecimento.

Aqueles que tramam sobre o corpo social, a fim de excluir, aniquilar a diversidade, para restringir uma determinada visão de mundo, para aumentar o seu poder e trazer estabilidade para o seu governo, apenas provoca um imenso dano à cultura. 0 exercício de ações como estas, que se manifestam na queima de livros, apenas demonstram como é possível a manipulação da sociedade. É essa obscura prática que está por trás da censura e da restrição da liberdade de expressão. Heinrich Heine já dizia que “onde se queimam livros, no fim, se queimam homens".

Todorov (2010), afirma que o medo dos bárbaros é a ameaça de nós mesmos nos tornarmos bárbaros. Em seguida, o medo torna-se perigoso para 
aqueles que percebem, e, portanto, não serem autorizados a assumir o papel de governar com desmedida paixão. São bárbaros os que vão para essas práticas, pregando essas limitações arbitrárias, aqueles que queimam livros em praças públicas. Nunca é tarde para o encontro legítimo entre a diversidade de valores, pois sempre há tempo para uma mudança de rumos. 0 encontro com nós mesmos faz crescer as sociedades.

\section{REFERÊNCIAS}

AGAMBEN, G. ¿Qué es um dispositivo? Sociológica, Ciudad de México, v. 26, n. 73, p. 249-364, 2011.

BÁEZ, F. El biblicausto nazi seguido de las primeras destrucciones de libros em China. Espéculo: Revista de Estudios Literarios, Madrid, n. 22, nov. 2002.

BERGER, P. L.; LUCKMANN, T. A construção social da realidade. 26. ed. Petrópolis: Vozes, 2006.

BORGES, J. L. A Biblioteca de Babel. In: . Ficções. São Paulo: Globo, 1999. v. 1.

BRADBURY, R. Fahrenheit 451. 2. ed. São Paulo: Globo, 2012.

CHARTIER, R. História da leitura no mundo ocidental. 1. ed. São Paulo: Ática, 1998.

Leer la lectura. In: SEMINÁRIO INTERNACIONAL “¿QUÉ LEER? ¿CÓMO LEER?”: PERSPECTIVAS SOBRE LA LECTURA EM LA INFANCIA, 2012, Santiago. Anais... Santiago: Plan Nacional de La Lectura, 2012. p. 1-17. Disponível em: <http://bit.ly/2vT9KU9>. Acesso em: 21 fev. 2015.

DELEUZE, G. Michel Foucault, filósofo. Barcelona: Gedisa, 1990. Crítica e clínica. 1. ed. São Paulo: Ed. 34, 1997.

ELIADE, M. Mito do eterno retorno. São Paulo: Mercuryo, 1992. FOUCAULT, M. A ordem do discurso. 2. ed. São Paulo: Loyola, 1996. . Vigiar e punir: nascimento da prisão. 20. ed. Petrópolis: Vozes, 1999. HALBWACHS, M. A memória coletiva. São Paulo: Centauro, 2004

JUNG, C. G. A estrutura da alma. In: A natureza da psique. 5. ed. Petrópolis: Vozes, 2000a. cap. 7. 
. Os arquétipos e o inconsciente coletivo. 2. ed. Petrópolis: Vozes, 2000b.

KANT, I. Resposta à pergunta: o que é Iluminismo? Covilhã: LosoSofia, [20--]. Disponível em: <http://bit.ly/2sUMyRM >. Acesso em: 13 fev. 2015.

LLORÉNS, V. Estudios y ensayos sobre el exílio republicano de 1939. Valencia: Editorial Renacimiento, 2006.

MONZÓN, C. Opinión pública, comunicación y política: la formación del espacio público. Madrid: Tecnos, 1996.

ORWELL, G. A revolução dos bichos. 1. ed. São Paulo: Claro Enigma, 2012. 1984. São Paulo: Companhia da Letras, 2009.

RICOUER, P. La identidad narrativa: sujeito y relato. Ciudad de México: UNAM, 2009. p. 341-355. Disponível em: <http://bit.ly/2xlyLF5>. Acesso em: 21 mar. 2015.

TODOROV, T. Memória do mal, tentação do bem. 1. ed. São Paulo: ARX, 2002.

. Frente al límite. Madrid: Siglo XXI, 2004.

Los abusos de la memória. Barcelona: Paidós, 2008.

. 0 medo dos bárbaros: para além dos choques da civilização. 1. ed.

Petrópolis: Vozes, 2010.

VALENCIA, L. O. La mezquindad organizada: sobre la quema del archivo fílmico del Colectivo Cine Forum. Proyecto Patrimonio, [Santiago de Chile], feb./abr. 2012a. Disponível em: <http://bit.ly/2vSwG5K>. Acesso em: 21 maio 2015.

Uma arqueologia del alma: ciência, metafísica y religión em Carl Gustav Jung. Santiago (Chile): Editorial USACH, 2012b.

WITTGENSTEIN, L. Tractatus lógico-philosophicus. 2. ed. bilínguie. rev. e ampl. São Paulo: EDUSP, 1994.

Recebido em: 19 de janeiro de 2014 Aceito em: 30 de agosto de 2017 